\title{
Incomplete Social Contracts
}

\section{Citation}

Aghion, Philippe, and Patrick Bolton. 2003. Incomplete social contracts. Journal of the European Economic Association 1(1): 38-67.

\section{Published Version}

doi:10.1162/154247603322256765

\section{Permanent link}

http://nrs.harvard.edu/urn-3:HUL.InstRepos:4554123

\section{Terms of Use}

This article was downloaded from Harvard University's DASH repository, and is made available under the terms and conditions applicable to Other Posted Material, as set forth at http:// nrs.harvard.edu/urn-3:HUL.InstRepos:dash.current.terms-of-use\#LAA

\section{Share Your Story}

The Harvard community has made this article openly available.

Please share how this access benefits you. Submit a story.

Accessibility 


\title{
INCOMPLETE SOCIAL CONTRACTS
}

Philippe Aghion

Harvard University and

University College London

\section{Patrick Bolton}

Princeton University

\begin{abstract}
There is a long normative 'Social Contract' tradition that attempts to characterize ex-post income inequalities that are agreeable to all 'behind a veil of ignorance.' This paper takes a similar normative approach to characterize social decision-making procedures. It is shown that quite generally some form of majority-voting is preferred to unanimity 'behind a veil of ignorance' whenever society faces deadweight costs in making compensating transfers. Deviations from unanimity (or ex-post Pareto optimality) are ex-ante efficient to the extent that they economize on costly compensating transfers. Put another way, the optimal decision rule trades off the benefits of minority protection and those from greater flexibility. (JEL: H11, G33, G34, D63, P16, P48)
\end{abstract}

... What, failing a prior agreement, is the source of the minority's obligation to submit to the choice of majority? ... The majority principle is itself a product of agreement, and presupposes unanimity on at least one occasion.

Jean-Jacques Rousseau

\section{Introduction}

In this paper we explore the consequences of contractual incompleteness for the design of optimal social contracts. Following a long tradition going back to Jean-Jacques Rousseau (1762), we analyze political institutions (constitutions) from the point of view of contracting "behind the veil of ignorance." Economic literature on this question [for example, Harsanyi (1955) and Mirrlees (1971)] has emphasized the risk-sharing role of political institutions and asked what kind of ex-post redistribution mechanisms society would choose to specify in a social contract written behind the veil of ignorance.

Acknowledgments: We wish to thank Daron Acemoglu, Abhijit Banerjee, Lucian Bebchuk, Guy Braibant, Joseph Brodley, Steven Coate, Dennis Epple, Leonardo Felli, Hans Gersbach, Mark Gradstein, Fausto Panunzi, Gerard Roland, Howard Rosenthal, Jean Tirole, Jörgen Weibull, two anonymous referees, and Torsten Persson (the editor) for very helpful suggestions and for useful references. We have also benefited from comments by seminar participants at University College London, Harvard Law School, London School of Economics, Princeton University, University of Pennsylvania, and the Canadian Institute for Advanced Research.

E-mail addresses: Aghion: p_aghion@harvard.edu; Bolton: pbolton@princeton.edu 
This literature does not consider the question of what decision-making procedures society would choose behind the veil of ignorance. We are primarily concerned with the latter question, albeit in the context of a redistribution problem. The question of design of ex-post decision-making procedures arises naturally in an incomplete contracting setting. Indeed, we begin by showing that if the social contract is complete (so that it can specify a state-contingent public good supply, taxation, and redistribution rule) then the optimal ex-post majority rule is unanimity. In other words, when a group of citizens must decide whether to move to a new position ex-post, the relevant social efficiency criterion is always whether the move is Pareto improving. The reason unanimity is optimal is that under this rule ex-post deviations from the social contract are most difficult to achieve. Since any form of ex-post deviation is suboptimal from an ex-ante perspective (when the social contract is complete), the social decision rule that prevents those deviations most effectively is optimal. And the most effective rule in this respect is unanimity.

One basic reason why a unanimity rule may be undesirable is that the social contract (or founding constitution) does not specify a decision-plan for all future contingencies. When some unusual event occurs for which a well-adapted decision is not specified in the social contract it may no longer be desirable from an ex-ante perspective to attempt at all cost to prevent deviations from the status-quo actions specified in the social contract. In our model it turns out that some form of majority voting is desirable quite generally when the social contract is incomplete. This is true despite two major drawbacks of majority voting.

First, when society agrees to abandon the unanimity rule in favor of some form of majority voting it is more likely to be exposed to Condorcet cycles. Under unanimity, cycling is less problematic since strict social preference orderings are transitive, and cycling can only occur on the Pareto frontier. In contrast, under majority voting Condorcet cycles arise even for strict preference orderings. This has been seen as an important reason for favoring a unanimity rule over majority voting. Indeed, Condorcet cycles have been perceived to be sufficiently problematic that a whole strand of literature in Social Choice has singled out the so-called min-max majority rule (see Caplin and Nalebuff 1988) as a good rule for ex-post social decisions. This super-majority rule is the closest rule to a 50 percent majority rule without Condorcet cycles. The basic reasoning in support of this rule is that it has the benefit of ruling out Condorcet cycles and it is the most flexible rule with this property (see, however, Dasgupta and Maskin 1997 for an alternative viewpoint).

Nevertheless, our analysis shows that from an ex-ante perspective, there is no strong reason a priori for choosing the min-max rule over any other majority rule. The basic point is that such a rule may not be flexible enough from an ex-ante perspective, and society may be prepared to pay the cost of "intrinsic uncertainty" introduced by the possibility of Condorcet cycles in order to get more ex-post flexibility. In our model, the term "flexibility" refers more explic- 
itly to the possibility of circumventing ex-post vested interests that may be opposed to the implementation of a valuable reform.

The second drawback of majority voting, which is the main focus of this paper, is that it may give rise to excessive ex-post redistribution, with the majority expropriating the minority. This is the well-known problem of the "tyranny of the majority." Once again, we show that from an ex-ante perspective society may be prepared to incur this cost for the sake of greater ex-post flexibility. However, the higher the scope for expropriation is the more stringent the optimal majority rule will be.

While greater flexibility and minimization of the cost of compensating vested interests pushes one towards reducing the required size of the majority, expropriation considerations push the ex-post decision rule towards super majority or unanimity. This trade-off between the costs of compensating vested interests and the costs of expropriating minorities determines our optimal majority rule.

Even though our approach is mainly normative, we believe that key elements of our theory are relevant for a positive theory of decision making in society. For example, decision making in the European Union can be (and has been) seen in similar terms to our theory. In the European Union decisions are made by the European Council of Ministers. Whereas important issues-such as EU enlargement, treaty changes, and some fiscal issues-require a unanimous vote within the Council, around 80 percent of the Council's more routine decisions are taken by a "qualified majority vote." A main proclaimed achievement of the recent Treaty of Nice has been the extension of qualified majority voting to new areas such as "trade in services and the commercial aspects of intellectual property" (Baldwin et al. 2001). Every step away from unanimity in EU decision making is hailed as an important victory for efficient decision making. On the other hand, when a group of countries successfully holds on to their veto right it is seen as a basic protection of sovereignty.

Our paper is related to an important body of literature in political science, and some of the ideas discussed here have a long ancestry. Buchanan and Tullock (1965) in particular, but also Rae (1969) and Taylor (1969) develop closely related ideas on majority voting rules. Our contribution can be seen as an attempt to refine and expand the formal analysis of Buchanan and Tullock. In this respect, the closest model to ours is Romer and Rosenthal (1983). ${ }^{1}$ Our model essentially extends Romer and Rosenthal (1983) by introducing, first contractual incompleteness, and second a positive deadweight cost of transfers. Both assumptions are key to obtain a unique interior solution to the optimal social contracting problem. Other recent incomplete contract approaches to constitutional design include: Persson, Roland, and Tabellini (1997) and Pers-

1. Romer and Rosenthal (1983) establish that with private information about payoffs, but no deadweight costs of transfers, a specific unanimity rule can implement the full information efficient solution. 
son and Tabellini (2000), who compare presidential and parliamentary regimes, and Gersbach (2002) and Erlenmaier and Gersbach (1999), who significantly extend our analysis by allowing for more general majority voting rules than in our paper. Finally, Aghion, Alesina, and Trebbi (2002) extend the incomplete social contract approach in this paper to analyze the costs and benefits of insulating political leaders (from changes in voters preferences or from aggregate shocks) and their implications for the design of political constitutions. They do so in a model in which political insulation plays a similar role to that of intellectual property right protection in a Schumpeterian model of innovation.

The paper is organized as follows. Section 2 develops our basic framework: it introduces our main notations, formalizes the benchmark case of complete social contracts, introduces the incomplete contracts assumption, and outlines our simple model of majority-voting. Section 3 derives the optimal majority rule and analyzes its comparative statics properties. Section 4 applies the basic model to the analysis of several important facets of constitution design, such as minority protections, vote trading, and federalism. Finally, Section 5 offers some concluding comments.

\section{The Model}

\subsection{Basic Setup}

As we already noted, the structure of our model is similar to Romer and Rosenthal (1983). ${ }^{2}$ They reduce the social choice problem to a problem of public good provision and financing and consider a two-period situation, where, to use their terminology, the first period is a constitutional period and the second a legislative period. In the constitutional period a polity of $N$ citizens must decide how public good provision and financing should be determined in the legislative period by designing a constitution which governs the process of political decision making in the legislative period.

Between the two periods a state of nature is realized that determines both the cost of providing different types of public good and their private benefits to each agent. We shall assume that there are $n$ different types of public goods that can be provided in the legislative period and that there are $n$ possible cost realizations $s_{i} \in\left\{s_{1}, s_{2}, \ldots, s_{n}\right\}$. To keep things as simple as possible we take the cost structure in each realization to be such that it is worth supplying at most one type of public good. That is, in each realization only one type of public good has a low per-capita cost of $c>0$ and all others have a prohibitively high cost, $k \gg c$. We adopt the convention that under cost realization $s_{i}$ the low cost type public good is type $i$. Thus in the legislative period (when the cost realization $s_{i}$ is known), the social choice problem reduces to choosing whether or not to produce public good $i$ and how to cover its cost. We denote by $p_{i}$ the ex-ante probability that cost $s_{i}$ is realized.

2. See also Laffont (1995) for a similar setup. 
The $N$ citizens differ in the utility they derive from the production of public good $i$. Let $b_{i j}$ denote agent $j$ 's private benefit from consumption of public good $i$. We assume that $b_{i j}$ can take two values, $b_{i j} \equiv B>0$ and $b_{i j}=-b<0$, so that the $N$ citizens can be divided into two categories: those who gain from the provision of public good $i$ and those who lose. We shall refer to a citizen with $b_{i j} \equiv B$ as 'fortunate' and one with $b_{i j}=-b$ as 'harmed.' The ex-ante probability that any one citizen is fortunate is given by $m_{i}$. We shall assume that each citizen's draw of utility type is identically and independently distributed. Thus if $N$ is sufficiently large (as we shall assume throughout the analysis), then the fraction of citizens who would benefit from the provision of public good $i$ is approximately equal to $m_{i}$. Combining the uncertainties on costs and utilities, we shall henceforth define a state of nature as any particular realization of the profile $\sigma_{i}=\left(s_{i},\left(b_{i j}\right)_{j}\right)$ for $1 \leq i \leq n$ and $1 \leq j \leq N$. Each citizen is also endowed with some private wealth $w^{j} \equiv w$. If we denote by $g_{i} \in\{0,1\}$ the supply of public good $i$, and by $\tau_{i j}$ citizen $j$ 's total tax payment in state $\sigma_{i}$, then we can write citizen $j$ 's payoff in state $\sigma_{i}$ as $w+b_{i j} g_{i}-\tau_{i j}$.

In the legislative period, the polity of $N$ citizens determines a choice of public good $g_{i}$ and a tax-policy $\tau_{i j}$, in light of the new information about the state of nature.

In the constitutional period all citizens are assumed to be identical, sharing the same probability distribution over cost-realizations $s_{i}$ and also over the realization of types $b_{i j}$ for any $s_{i}$. The ex-ante uncertainty about costs and benefits is resolved sequentially, with cost realization $s_{i}$ occurring before the realization of utility types $b_{i j}$.

Thus, just as in the model of Romer and Rosenthal, the citizens must design a constitution or (incomplete) social contract governing the supply of public goods in the legislative period "behind the veil of ignorance." Each citizen's objective at that time is then to maximize his net expected benefits from the provision of public goods. We shall assume that under the feasible constitutional arrangements available the net expected benefit is strictly positive, so that all $N$ citizens have an incentive to join the polity at this stage.

A key departure from Romer and Rosenthal (1983), besides our assumption of incompleteness of the social contract, is to assume that there is a deadweight cost of taxation at the legislative stage, which for simplicity we take to be linear. We denote by $\lambda>0$ the cost of raising one unit of public funds. One interpretation of this cost is simply that it represents a collection cost, or the administrative cost of transferring funds. Another possible interpretation is that $\lambda$ reflects the disincentive to work or effort if wages are taxed (see Aghion and Bolton 2002).

Unlike Romer and Rosenthal (1983) we also assume that all payoffs $b_{i j}$ are observable in the legislative period (except in Section 4.2). Before describing the nature of contractual incompleteness we shall briefly consider the optimal complete contingent social contract. 


\subsection{Complete Contingent Social Contracts}

Suppose that in the constitutional period citizens are able to foresee all possible future states of nature and to agree on a common description of the complete state space. In this case the citizens are able to specify in advance what public good should be supplied and how it should be financed in every state of the world. In other words, the citizens are able to write a completely contingent social contract $\left\{\left(g_{i}(\sigma), \tau_{i j}(\sigma)\right)_{i, j}\right\}$.

Note that in the constitutional period citizens always (weakly) prefer to write a complete social contract, if they can, leaving no room for any new choices to be made in the future. Indeed, by writing a complete constitution they can always replicate any outcome that would have been attained with an incomplete constitution. In addition, some outcomes may be attainable only if they are specified before the state of nature is realized and all citizens have learned their preferences and positions in society.

An implicit assumption here is that citizens in our model only have preferences over final outcomes and do not derive any intrinsic benefit from future freedom of choice. It could be argued that this is a misrepresentation of people's preferences and that in reality people value the fact that the future is not entirely predetermined. It is beyond the scope of this paper to address this important issue. As will become clear in the next section, however, our analysis does not crucially depend on a specific modelling of preferences. Since we assume later that it is not technologically feasible to write a complete social contract we do not need to take up the question of whether citizens would want to determine all future actions if they could.

Since all citizens are identical in the constitutional period, they unanimously prefer the social contract that maximizes their expected payoff,

$$
w+\sum_{i=1}^{n} p_{i}\left[m_{i}\left(B-\tau_{i B}\right)-\left(1-m_{i}\right)\left(b-\tau_{i b}\right)\right] g_{i} .
$$

where, $\tau_{i B}$ and $\tau_{i b}$, respectively, denote the tax contributions of a citizen with private benefit $B$ for public good $i$ or $-b$. Thus, in the constitutional period citizens adopt the complete constitution $\left\{g_{i}, \tau_{i B}, \tau_{i b}\right\}$, which solves the following program:

$$
\max _{\left\{g_{i}, \tau_{i B}, \tau_{i b}\right\}} w+\sum_{i=1}^{n} p_{i}\left[m_{i}\left(B-\tau_{i B}(1+\lambda)\right)-\left(1-m_{i}\right)\left(b-\tau_{i b}\right)\right] g_{i}
$$

subject to the budget constraint ${ }^{3}$ :

$$
\left[m_{i} \tau_{i B}-\left(1-m_{i}\right) \tau_{i b}-c\right] g_{i}=0
$$

3. Note that the distortionary cost $\lambda$ is only incurred when raising taxes from each individual in the economy. 
One solution to this program is straightforward and is given by:

$$
\left\{\begin{array}{l}
g_{k}(\sigma)=0 \quad \text { for all } k \neq i \text { and, } \\
g_{i}(\sigma)=1 \quad \text { if and only if }\left[m_{i} B-\left(1-m_{i}\right) b\right]>c(1+\lambda) . \\
\text { with associated tax rule: } \\
\tau_{j}^{k}(\sigma)=0 \quad \text { for all } k \neq i \text { and, } \\
\tau_{i B}=0 \quad \text { if } g_{i}(\sigma)=0, \\
\tau_{i B}=\frac{c(1+\lambda)}{m_{i}} \quad \text { if } g_{i}(\sigma)=1, \quad \text { and } \tau_{i b}=0 .
\end{array}\right\}
$$

Note that since this allocation is Pareto-efficient in every state $\sigma$, it does indeed maximize the ex-ante utility of a citizen. Note also that the complete social contract specifies no compensation for those who are harmed by the production of the public good. The reason is simply that a subsidy $\tau_{i b}$ involves a deadweight cost of transfers of $\lambda \tau_{i b}$ and from an ex-ante perspective, when the citizen's position in society is not yet known, it is always preferable to reduce this deadweight cost as much as possible. Of course, if citizens were risk-averse with respect to their future position in society, they would want to allow for some form of insurance, which would involve a positive $\tau_{i b}$. However, they would then trade off the benefits of insurance against the deadweight costs of taxation, so that they would not want full insurance in general. ${ }^{4}$

Finally, note that because the solution under a complete social contract is Pareto-efficient in every state $\sigma$, the contract will not be renegotiated under a unanimity rule. Thus, if the social contract specifies a unanimity rule to change any terms of the contract in the legislative period it will be immune to renegotiation. Because renegotiation of a complete social contract can only make things worse for the founders of the constitution it is optimal for them to make it as difficult as possible to change the constitution by giving a veto power to every citizen in the legislative period.

\subsection{Incomplete Social Contracts}

We shall now consider a more realistic set of social contracts that do not specify a complete state-contingent public-good-supply-plan. A common assumption in the incomplete contracting literature, which we also make here, is to assume that future states of nature are not ex-post verifiable and that all the constitution can do is to specify a state-independent production plan together with decisionmaking rules for the choice of public good supply in the legislative period. ${ }^{5}$

4. One might want to argue that citizens should be able to avoid all deadweight cost of insurance by setting up an insurance fund in the constitutional period to which all citizens would be willing to contribute. In that case, the solution would be the same whether citizens are risk-averse or not.

5. In particular, we rule out mechanisms where the decision to produce the public good or not and the allocation of taxes and subsidies across agents would depend on messages sent by agents ex post. 
Most, if not all, existing constitutions say very little about the size of government or the nature of government activities. They are instead devoted to a detailed specification of rules for future social decision making. The constitutions we consider in this model, if anything, specify too much rather than too little in terms of future public good supply relative to what is actually specified in existing constitutions.

Thus, the incomplete social contracts we consider in the remainder of this paper can only specify:

1) a status-quo, with a production decision $g=g_{s}$ and a tax rule $\left(\tau_{s j}\right)$, which both are independent of the state realization;

2) a decision rule for changing the public good decision in the legislative period once the state of nature is realized.

We shall restrict attention to incomplete social contracts with status-quo $\left\{g_{i}=0\right.$ for all $i, \tau_{i j}=0$ for all $\left.j\right\} .{ }^{6}$ Also, we shall assume for now that the social contract cannot impose any restrictions on tax rates.

\subsection{A Simple Model of Majority Voting}

As mentioned in the introduction, there are two drawbacks with majority voting that are often emphasized. First, the majority may be tempted to exploit the minority. Second, with no restrictions on feasible tax schemes, majority voting gives rise to cyclic voting. Because of these drawbacks it is not clear a priori that majority rule would necessarily dominate unanimity. Also, because of cyclic voting it is not clear what the outcome is under majority voting. The final outcome will be driven by the objectives of whomever happens to have control over the agenda, and in the constitutional period it is difficult to predict who will be the agenda setters in the legislative period. Alternatively, even if the agenda setters could be determined in the constitutional period, uncertainty about their preferences would remain.

We determine the outcome of majority voting when there is cycling as follows. Assuming that there is a net per-capita gain in supplying the public good, we take a majority coalition to include first, all those who gain from the public good (the 'fortunate' citizens in our terminology). Second, if the total number of fortunate citizens is not sufficient to form a majority a residual number of 'harmed' citizens is also part of the majority coalition. ${ }^{7}$ The harmed citizens in the majority coalition are picked at random from the population of harmed citizens. In situations where the number of fortunate citizens is larger than the majority requirement, members of the majority are picked at random among the fortunate citizens. The agenda setters in the majority coalition are

6. See our discussion paper, Aghion and Bolton (2002) for an analysis of other status-quo points.

7. It is actually always optimal for an agenda setter(s) to include as many fortunate citizens as possible in the majority, as this minimizes the cost of compensating those who are made worse off by the public good. 
always taken to be fortunate agents. To get a majority to vote for their plan, when fortunate citizens are not a majority in the population, the agenda setters may need to compensate the harmed citizens in their majority.

Once a majority coalition has been determined in this way a public good supply and tax scheme is put to a vote. The outcome is either the status-quo, if the proposal is defeated, or the proposed change, if a majority of $m_{l}$ citizens votes in favor.

In an earlier version we have explored a slightly different, perhaps more satisfactory specification of majority voting. In this specification an agenda setter was selected at random in the whole population to propose a plan. This specification yields the same qualitative predictions. Although maybe simpler to explain and understand, the algebra under this formulation is unfortunately less tractable and transparent.

We assume throughout the paper that when a voter is indifferent between the status-quo outcome and the proposed change he votes in favor of the change.

To summarize, the timeline of moves and events in our model is as follows:

1. at date 0 a constitution is written specifying: a) agenda setting rules in the legislative period; b) a majority rule $m_{l}$; c) a status-quo point,

2. at date 1 a state of nature $\sigma_{i}=\left(s_{i},\left(b_{i j}\right)_{j}\right)$ is realized, agents learn their payoffs and the cost of production of public goods (recall that only one public good has sufficiently low cost that it is worth producing),

3. fortunate citizens form a coalition, which has control over the agenda; if the fraction $m_{i}$ of fortunate citizens exceeds the majority requirement $m_{l}$, then the $\mathrm{Nm}_{l}$ fortunate citizens who form the coalition is drawn at random from the population of fortunate citizens $\mathrm{Nm}_{i}$; if the fraction $m_{i}$ of fortunate citizens is less than the majority requirement $m_{l}$ then all fortunate citizens form the coalition and select $N\left(1-m_{l}\right)$ harmed citizens at random from the population of harmed citizens $N\left(1-m_{i}\right)$ to join the majority coalition,

4. the coalition taking control of the agenda proposes a budget specifying provision of a public good $g_{i}$ and a tax scheme $\left(\tau_{i j}\right)$, which can be made contingent on whether the taxed individual is in the majority or the minority,

5. all agents vote in favor or against the proposed budget,

6. if the budget is approved by the required majority $N m_{l}$ it is implemented,

7. if it is not, the status-quo is implemented.

8. Finally all agents consume their after-tax wealth.

We shall also consider vote trading between Stages 4 and 5 .

\section{The Optimal Majority Rule}

\subsection{Stating the Optimization Problem}

Suppose that a majority of $N m_{l}$ citizens is required to reach a decision (the subscript $l$ stands for legislative majority). Consider the decision problem faced 
by the agenda setters in the majority in any state $\sigma_{i}$. They must first determine whether to set $g_{i}=1$ or $g_{i}=0$ and then how to structure income taxes.

If they decide to set $g_{i}=0$, the fortunate citizens in the majority 'expropriate' the minority of their wealth endowment $w$ and share the proceeds among themselves. Their per-capita payoff is then

$$
w+\frac{\left(1-m_{l}\right) w(1-\lambda)}{\min \left(m_{i}, m_{l}\right)} .
$$

That is, each fortunate citizen in the majority gets to keep their wealth endowment and also shares the net tax receipts from the minority $N\left(1-m_{l}\right) w(1-\lambda)$ (recall that $\lambda$ denotes the unit deadweight cost of taxation).

If the majority offers to set $g_{i}=1$, the minority is again expropriated. In addition, each fortunate citizen in the majority obtains a benefit

$$
B-\frac{\left(m_{l}-m_{i}\right)^{+} b+c}{\min \left(m_{i}, m_{l}\right)} .
$$

The first term is the utility benefit of the public good. The second term is the cost of the public good. Given that the minority is fully expropriated and the harmed citizens in the majority must be kept indifferent between voting for or against the plan, the cost of producing the public good $N c$ is entirely borne by the fortunate citizens (in total number of $N \min \left(m_{i}, m_{l}\right)$ ). In addition the fortunate citizens must bear the cost of compensating the harmed citizens in the coalition $\left(m_{l}-m_{i}\right)^{+} b$, so as to keep them indifferent.

A necessary and sufficient condition for the majority to produce the public good in state $\sigma_{i}$ is then:

$$
(I C): B \min \left(m_{i}, m_{l}\right)-b\left(m_{l}-m_{i}\right)^{+} \geq c,
$$

and

$$
(B C): w \min \left(m_{i}, m_{l}\right)+\left(1-m_{l}\right) w(1-\lambda) \geq c+b\left(m_{l}-m_{i}\right)^{+} .
$$

The first (incentive) condition states that the majority coalition prefers to produce the public good. The second (budget) condition states that the majority coalition is able to generate enough funds to cover the cost of production. ${ }^{8}$

We shall assume throughout the paper that $B$ and $w$ are sufficiently large

8. Note that we assume here that only minority individuals are taxed, while majority individuals voluntarily contribute to the cost of the public good, with a lower transfer cost that we normalize at zero. Had we assumed instead that majority individuals are also taxed with the same distortionary $\operatorname{cost} \lambda$ for the amount necessary to finance the cost of the public good plus the compensation of majority members who are harmed by the public good the budget condition would be:

$$
(B C): w \min \left(m_{i}, m_{l}\right)+\left(1-m_{l}\right) w(1-\lambda) \geq\left[c+b\left(m_{l}-m_{i}\right)^{+}\right](1+\lambda) .
$$

This formulation is slightly less elegant and transparent. This is why we do not pursue it in the core of the paper. Observe also that there are basic economic reasons why the cost of taxing those who gain from a public decision would be lower. These citizens will show more goodwill to the tax authorities and will be more willing to comply. To simplify the exposition we make the extreme 
that it is always efficient and feasible to produce the (low-cost) public good. That is:

Assumption A1

$$
\begin{aligned}
B m_{i}-b\left(1-m_{i}\right) & \geq c, \quad \text { and } \\
w m_{i}+w\left(1-m_{i}\right)(1-\lambda) & \geq c .
\end{aligned}
$$

Under this assumption, condition (IC) is never binding in equilibrium, as we shall verify next. On the other hand, the budget condition (BC) will always be binding in equilibrium if the optimal rule $\mathrm{m}_{1}$ is interior to the interval $(0,1)$. When the budget condition holds, the public good is supplied and the ex-post payoff of a fortunate citizen in the majority is then given by

$$
\pi_{i}^{1}\left(m_{l}\right)=w+B-\frac{\left(m_{l}-m_{i}\right)^{+} b+c}{\min \left(m_{i}, m_{l}\right)}+\frac{\left(1-m_{l}\right) w(1-\lambda)}{\min \left(m_{i}, m_{l}\right)} .
$$

And, the ex-ante expected payoff in state $\sigma_{\mathrm{i}}$ is then

LEMMA 1 The ex-ante expected payoff under a majority rule $m_{l}$ satisfying condition $(B C)$ is equal to:

$$
\Pi_{i}^{1}\left(m_{l}\right)=w+m_{i} B-\left(1-m_{i}\right) b-c-\lambda\left(1-m_{l}\right) w .
$$

Proof We need to consider two cases:

(1) if $m_{l}>m_{i}$, then, using the fact that harmed citizens in the majority are made just indifferent between producing the public good or not:

$$
\begin{aligned}
\Pi_{i}^{1}\left(m_{l}\right)= & m_{i} \pi_{i}^{1}\left(m_{l}\right)+\left(m_{l}-m_{i}\right) w-\left(1-m_{l}\right) b \\
= & m_{i}(B+w)-\left(m_{l}-m_{i}\right) b-c+\left(1-m_{l}\right) w(1-\lambda) \\
& +\left(m_{l}-m_{i}\right) w-\left(1-m_{l}\right) b \\
= & w+m_{i} B-\left(1-m_{i}\right) b-c-\lambda\left(1-m_{l}\right) w .
\end{aligned}
$$

(2) if $m_{l}<m_{i}$ then the fortunate citizens in the minority are expropriated and ex-ante payoffs are:

assumption that this cost is zero. As will become clear, this assumption is not critical for our results. Our main conclusions and comparative statics would hold under the alternative assumption that tax collection costs are the same for all. 


$$
\begin{aligned}
\Pi_{i}^{1}\left(m_{l}\right) & =m_{l} \pi_{i}^{1}\left(m_{l}\right)+\left(m_{i}-m_{l}\right) B-\left(1-m_{l}\right) b \\
& =m_{l}\left[w+B-\frac{c}{m_{l}}+\frac{\left(1-m_{l}\right) w(1-\lambda)}{m_{l}}\right]+\left(m_{i}-m_{l}\right) B-\left(1-m_{i}\right) b \\
& =w+m_{i} B-\left(1-m_{i}\right) b-c-\lambda\left(1-m_{l}\right) w .
\end{aligned}
$$

This establishes the lemma. QED

Under a majority rule $m_{l}$ that does not satisfy condition $(B C)$ the public good is not produced and ex-ante expected payoffs are simply:

$$
\Pi_{i}^{0}\left(m_{l}\right)=w-\lambda\left(1-m_{l}\right) w .
$$

Abstracting from the incentive constraint (IC), which never binds in equilibrium under Assumption A1, the optimal majority rule $m_{l}$ is defined as the one that maximizes the ex-ante mean payoff:

$$
\Pi\left(m_{l}\right)=\sum_{i} p_{i}\left[\Lambda \Pi_{i}^{\Lambda}\left(m_{l}\right)+(1-\Lambda) \Pi_{i}^{(1-\Lambda)}\left(m_{l}\right)\right],
$$

where $\Lambda=\Lambda\left(m_{i}, m_{l}\right)$ is an indicator function taking the value $\Lambda=1$ when the budget constraint $(B C)$ is satisfied, and $\Lambda=0$ otherwise.

\subsection{The Basic Trade-off}

We are now in a position to illustrate the main trade-off between reducing the deadweight cost of taxation and ensuring an efficient supply of public goods. We shall only consider this trade-off in the special case where the fraction of fortunate citizens is the same in all states: $m_{i} \equiv \hat{m} .{ }^{9}$ If we ignore for now the incentive constraint $(I C)$ then under assumption A1 the optimal majority rule $m_{l}$ minimizes the deadweight loss from expropriation $\lambda\left(1-m_{l}\right) w$ subject to satisfying the budget condition $(B C)$. This is equivalent to maximizing $m_{l}$ subject to satisfying the budget constraint.

Therefore, at the optimum constraint $(B C)$ binds and the optimal majority rule is given by:

$$
m_{l}^{*}=\min \left\{\frac{(w+b) \hat{m}+w(1-\lambda)-c}{w(1-\lambda)+b}, 1\right\}
$$

provided that $m_{l}^{*} \geq \hat{m}$. It is easy to see that under assumption A1 this inequality always holds.

Moreover, it is also easy to check that when

$$
w \hat{m} \leq c+b(1-\hat{m})
$$

we have $m_{l}^{*}<1$.

9. See our discussion paper, Aghion and Bolton (2002), for an analysis of the general case where $m_{i}$ is random. 
Suppose first that condition (4) holds. When we substitute for the value of $m_{l}^{*}$ in $\Pi_{i}^{1}\left(m_{l}\right)$ we obtain an ex-ante payoff:

$$
\Pi_{i}^{1}\left(m_{l}^{*}\right)=w+\hat{m} B-(1-\hat{m}) b-c-\frac{\lambda w \max \{b(1-\hat{m})+w \hat{m}-c, 0\}}{w(1-\lambda)+b} .
$$

Next, of all the majority rules that violate $(B C)$, the best one is clearly unanimity $\left(m_{l}=1\right)$ as this rule precludes any scope for expropriation.

Hence, when condition (4) holds, $m_{l}^{*}$ will dominate unanimity with no public good provision if and only if:

$$
\Pi_{i}^{0}(1)<\Pi_{i}^{1}\left(m_{l}^{*}\right)
$$

Or, equivalently, if and only if:

$$
\hat{m} B-(1-\hat{m}) b-c>\frac{\lambda w[b(1-\hat{m})+w \hat{m}-c]}{w(1-\lambda)+b} .
$$

Note finally that under Assumption A1 the incentive constraint (IC) is satisfied for majority rule $m_{l}^{*}$. To see this it suffices to observe that $m_{l}^{*} \geq \hat{m}$.

Suppose now that condition (4) does not hold. Then, obviously unanimity is optimal because it prevents any form of expropriation and it is still feasible to fund the cost of the public good as well as the compensation of all those who are harmed by the provision of the public good.

We have thus established:

Proposition 1 Under assumption Al the optimal majority rule is given by:

$$
m_{l}^{*}=\frac{(w+b) \hat{m}+w(1-\lambda)-c}{w(1-\lambda)+b}
$$

whenever conditions (4) and (5) hold. The public good is then produced at minimum deadweight loss. Otherwise, the optimal rule is unanimity and the public good is produced if and only if $w \hat{m} \geq c+b(1-\hat{m})$.

Proof See the discussion above. QED

This proposition delivers interesting comparative statics properties. In particular, the rule $m_{l}^{*}$ is a decreasing function of the taxation cost $\lambda$ and the production cost $c$ : an increase in either of these costs will push one towards reducing the majority requirement $m_{l}$ in order to guarantee that the public good can be financed. On the other hand, when $\lambda$ increases, condition (5) is harder to satisfy. Therefore, beyond a certain point an increase in $\lambda$ and/or $c$ will result in a jump in the optimal majority rule to $m_{l}=1$. Thus, there is a nonmonotonic relation between $m_{l}$ and $\lambda$. Starting from low values of $\lambda$ an increase in this parameter lowers the optimal majority rule, but beyond a certain point it increases it. 
Notice also that $m_{l}^{*}$ is an increasing function of citizens' initial wealth $w$ : an increase in $w$ raises the super-majority rule because there is more to expropriate. ${ }^{10}$ The majority rule is also decreasing in $b^{11}$ : an increase in $b$ results in a less stringent majority rule in order to reduce the cost of compensation and thereby facilitate public good provision.

\subsection{Asymmetric Information}

It is generally not possible in practice to know exactly each voter's payoff. That is, even if the distribution of preferences in the population may be commonly known it is not possible to know each voter's preferences. But our theory so far has relied on the assumption that fortunate citizens can be identified and combined in a majority supporting public good provision. We have also relied on the assumption that if a group of harmed citizens must be persuaded to join the majority coalition then only that group will be targeted with compensating transfers. When individual voters' preferences are private information wouldn't every member joining the majority coalition insist on getting a compensating transfer? If so, wouldn't that undermine our whole theory?

We show in this section that this is not necessarily the case. Even though more compensating transfers need to be made under private information to build a majority coalition the theory developed under the simplifying assumption of complete information is essentially unchanged.

To see this, suppose that the fraction $m_{i} \equiv \hat{m}$ (respectively $1-m_{i}$ ) of individuals with utility $B$ (respectively $-b$ ) in any state $\sigma_{i}$ is common knowledge, but that a particular individual's payoff is private information. Also, suppose that nature selects a fortunate individual at random to be the agenda setter. This agenda setter still needs to compensate a positive fraction of 'harmed citizens' in the population in order to secure a majority $m_{l}$ in favor of producing the public good whenever $\hat{m}<m_{l}$.

The key question with privately known preferences is how big a fraction of voters need the agenda setter compensate? We shall show that this fraction need not be substantially larger than $\left(m_{l}-\hat{m}\right)$. If he pays $b$ to a fraction $x$ of voters, by the law of large numbers this will make $(1-\hat{m}) x$ harmed citizens vote in favor of producing the public good. Therefore, after being promised this compensation the total number of voters in favor of public good provision will be:

$$
(1-\hat{m}) x+\hat{m} \text {. }
$$

10. Differentiating (3) with respect to $w$, we have:

$$
\frac{d m_{l}^{*}}{d w}=\frac{\lambda b \hat{m}+(b+c)(1-\lambda)}{(w(1-\lambda)+b)^{2}}>0 .
$$

11. We have:

$$
\frac{d m_{l}^{*}}{d b}=\frac{-(1-\hat{m}) w(1-\lambda)-\hat{m} w+c}{(w(1-\lambda)+b)^{2}},
$$

which is negative when $m_{l}^{*}>\hat{m}$ as a result of $(B C)$. 
For a majority of voters to support provision of the public good this number needs to be greater than or equal to the majority requirement $m_{l}$. That is, the fraction $x$ must be at least equal to:

$$
x^{*}=\frac{\left(m_{l}-\hat{m}\right)^{+}}{1-\hat{m}} .
$$

Note that although this fraction is higher than the fraction of harmed citizens $\left(m_{l}-m_{i}\right)^{+}$that are compensated under symmetric information it is far from being equal to $m_{l}$. As more compensating transfers are needed under asymmetric information about preferences the budget constraint $(B C)$ for public good provision will be tighter than that under symmetric information:

$$
\left(B C_{a i}\right): w \min \left(m_{l}, \hat{m}\right)+w(1-\lambda)\left(1-m_{l}\right) \geq \frac{\left(m_{l}-\hat{m}\right)^{+}}{1-\hat{m}} b+c .
$$

As a result, the optimal majority rule under asymmetric information-for which the incentive constraint $\left(B C_{a i}\right)$ is binding-will be lower. ${ }^{12}$ That is:

$$
m_{l}^{a i}=\frac{[w(1-\hat{m})+b] \hat{m}+[w(1-\lambda)-c](1-\hat{m})}{w(1-\lambda)(1-\hat{m})+b},
$$

which is strictly lower than the optimal majority rule under symmetric information

$$
m_{l}=\frac{(w+b) \hat{m}+w(1-\lambda)-c}{w(1-\lambda)+b} .
$$

We have thus established:

PROPOSITION 2 When voters' preferences are private information the compensation costs required to form a majority are larger and the optimal majority rule is lower and given by:

$$
m_{l}^{a i}=\max \left\{\hat{m}, \frac{[w(1-\hat{m})+b] \hat{m}+[w(1-\lambda)-c](1-\hat{m})}{w(1-\lambda)(1-\hat{m})+b}\right\} .
$$

It is not surprising that more compensating transfers are needed when 'harmed citizens' cannot be identified precisely. It is also not surprising that the constitution designers would lower the majority requirement if compensation costs are higher and the risks of expropriation of the minority lower (because the agenda setter must, so to speak, cast a wider net to be sure of getting a sufficient majority supporting his policy). What is slightly more surprising is that the agenda setter must not compensate a wider fraction of voters than

12. We can ignore the incentive constraint $(I C)$ because it is unaffected by information asymmetry about preferences. 


$$
x^{*}=\frac{\left(m_{l}-\hat{m}\right)^{+}}{1-\hat{m}} .
$$

It is interesting to contrast our result here with the analysis of Romer and Rosenthal (1983). They establish that with private information about payoffs but no deadweight costs of transfers, a unanimity rule together with highly inefficient status-quo points can implement the full information efficient solution. Such a solution would be inefficient in our setting precisely because it requires large transfers and therefore also imposes large deadweight costs of transfers.

We close this subsection with two remarks:

REMARK 1 In the discussion here we have continued to assume that those who benefit from the public good will continue to contribute their share of the cost of the public good at no deadweight loss. This assumption is not necessarily inconsistent with private information about preferences if the lower cost of taxation is due to greater goodwill towards the tax authorities and greater willingness to comply among those who benefit from public policies, as we have argued. In the extreme case where any fortunate citizen behaves exactly as if she were harmed by the public policy the budget constraint would become:

$$
\left(B C_{a i}\right): w \min \left(m_{l}, \hat{m}\right)+w(1-\lambda)\left(1-m_{l}\right) \geq\left[\frac{\left(m_{l}-\hat{m}\right)^{+}}{1-\hat{m}} b+c\right](1+\lambda),
$$

and the optimal majority rule would be reduced even further to:

$$
m_{l}^{a i}=\max \left\{\hat{m}, \frac{[\tilde{w}(1-\hat{m})+b] \hat{m}+[\tilde{w}(1-\lambda)-c](1-\hat{m})}{\tilde{w}(1-\lambda)(1-\hat{m})+b}\right\},
$$

where

$$
\tilde{w}=\frac{w}{1+\lambda} .
$$

In this extreme case also it may not always be feasible to fund the cost of the public good under assumption A1. A stronger condition is then required.

REMARK 2 Tax and subsidy policies targeted at particular citizens may be seen to be unrealistic. That is, differential treatments between two citizens who appear to be identical ex ante may seem far-fetched. However, in reality, there are many instances of different treatment across regions, districts or professions. Thus, the tax/subsidy policy described here should be interpreted as illustrating such forms of targeted policies.

\section{Applications to Constitution Design}

We have shown that when social contracts (or constitutions) are highly incomplete the optimal majority rule can be determined from a simple trade-off 
between minimizing the costs of compensating entrenched vested interests and protecting minorities from expropriation. We have also shown that the basic analysis is robust to the introduction of asymmetric information. In this section we use this basic theory and our simple framework to shed light on other important aspects of the design of constitutions. We begin by analyzing several important minority protections that are found in most constitutions. These protections range from basic human rights to absolute ceilings on taxation. We then proceed with a discussion of the difficult and contentious issue of vote trading. Finally, we conclude with a discussion of the costs and benefits of federalism and the role of bicameralism.

\subsection{Minority Protection}

In this subsection we consider several minority protections that are commonly found in constitutions: amendment rights, constitutional limits on taxation, and equal tax rules. We determine how these rules affect the optimal majority rule and ex-ante welfare. A broad intuition applies to all these rules: to the extent that they reduce the scope for expropriation they should result in lower optimal majority requirements than would be the case in the absence of minority protections. Whether lower majority rules combined with minority protections raise ex-ante welfare, however, is a priori not obvious.

4.1.1. Amendment Rights Many constitutions allow members of the legislature to make amendments to a bill proposed by a committee or the government. Obviously, the power to make such amendments raises the power and protection of a minority ex-post. We shall follow Baron and Ferejohn (1987, 1989) and model amendment rights in a highly stylized way as follows. Suppose that the legislative process takes two successive rounds. The first round is as before, with the majority of fortunate citizens acting as agenda-setters and putting a bill to a vote. If the bill is passed by the required majority the legislature adjourns. Otherwise, if the unamended bill is not passed in the first round, we allow harmed citizens in the majority to propose an amendment and set the new agenda in a second round. If the required majority votes in favor of the amended bill in the second round it is passed. Otherwise, the status-quo is implemented. No more than two rounds during the whole legislative process need be considered to analyze amendment rights in our model. All individuals have the same discount factor $\delta$ between the two rounds.

Let us reason by backward induction, and suppose that the first bill has been rejected, so that it is up to the agenda-setters in the second round to make a new proposal. In equilibrium, the agenda setters in the second round will be able to extract up to

$$
\min (\hat{m} B, \hat{m} w)=\Omega,
$$

from the fortunate citizens in exchange for agreeing to supplying the public good $(\Omega$ is equal to the minimum of what the fortunate citizens are willing or able to pay). Now, moving back to the first round, if the majority does not agree 
to transfer the amount $\Omega$ to the harmed citizens in the majority, these are better off rejecting the fortunate citizens' proposal in the first round and proposing an amended bill in the second round. Thus the budget condition for public good provision now becomes:

$$
\left(B C_{a r}\right): \hat{m} w+\left(1-m_{l}\right) w(1-\lambda) \geq c+b\left(m_{l}-\hat{m}\right)+\Omega .
$$

As before the optimal majority rule will minimize the deadweight loss $\lambda(1-$ $\left.m_{l}\right) w$ subject to $\left(B C_{a r}\right)$. At the optimum, the constraint will again be binding, which in turn yields the new optimal majority rule:

$$
m_{l}^{a r}=\max \left\{\hat{m}, \frac{(w+b) \hat{m}+w(1-\lambda)-c-\delta \Omega}{w(1-\lambda)+b}\right\},
$$

which is smaller than the optimal majority requirement in the absence of amendment rights.

This latter conclusion, in turn immediately implies that the ex-ante expected welfare of a representative individual

$$
\Pi_{i}^{1}\left(m_{l}\right)=w+\hat{m} B-(1-\hat{m}) b-c-\lambda\left(1-m_{l}\right) w
$$

is reduced by introducing amendment rights. This is not entirely surprising: amendment rights require a larger compensation of harmed citizens ex post. This, in turn, forces a reduction in the majority requirement ex ante for the budget constraint to still hold with the higher compensation requirements of harmed citizens in the majority coalition. This has the effect of increasing the scope for inefficient expropriation. We highlight this conclusion in the following proposition.

PROPOSITION 3 Amendment rights result in a lower optimal majority requirement and increase the scope for expropriation sufficiently to lower ex-ante expected payoffs for the representative citizen.

Note that this result would be unchanged if we also allowed members of the minority to make amendments in the second round. The reason is simply that these members cannot affect the outcome of voting in the first round.

If amendment rights reduce welfare, why then are they so prevalent? What elements of reality are we missing in our simple model? For one, an important simplifying assumption in our model is that all citizens are risk neutral. If they were risk averse, amendment rights might possibly be an optimal way of providing insurance and reducing the variance of ex-post payoffs, even if they also increase the deadweight costs of expropriation. Another rationale behind amendment rights is that they lead to better laws that are more fine-tuned to the particular needs of a subset of citizens.

4.1.2 Equal Tax Rates Another way of providing minority protections is through equal treatment rules. In our stripped-down model such rules might translate 
into equal tax rules. We show in this subsection that the effects of such a rule are rather subtle. Under some circumstances (e.g., when deadweight costs of transfers are relatively low) such a rule may not provide any protection to the minority against expropriation and may be counterproductive. However, under other circumstances the rule has the effect of inducing the majority to lower the tax burden and thus provides a welfare improving protection.

Note first that if the constitution requires all individuals to bear the same tax burden this rule would not make any difference in our model if, as we have assumed so far, the agenda setters are free to redistribute tax revenues as they please and if there are no deadweight costs of transferring public funds beyond tax collection costs from harmed citizens.

For more general specifications of deadweight costs of public transfers one suspects, however, that an equal tax rule ought to have some bite and might increase ex-ante welfare by reducing the scope for expropriation of the minority. Accordingly, suppose for the sake of argument that the same distortionary cost $\lambda$ applies to all individuals and all transfers, whether taxes collected or redistributed. Under this specification of deadweight costs there are even greater benefits than before in avoiding unnecessary or redundant transfers. That is, there are larger savings from eliminating taxes and subsidies to an individual citizen that cancel one another out.

With this new specification of deadweight costs of transfers the budget condition takes the form

$$
\left(B C_{e t}\right): w(1-\lambda) \geq\left[c+(b+w)\left(m_{l}-\hat{m}\right)\right](1+\lambda),
$$

where the LHS represents maximum tax revenues net of the distortionary cost of tax collection, and the RHS is the total expenditure towards the cost of the public good and the compensating transfers to harmed citizens in the majority coalition. When this budget condition is slack there are two possibilities for ex-post tax policy:

1. the (equal) tax rate is reduced to the point where the budget constraint is binding in order to save on costly public transfers,

2. taxes are kept high and unspent tax revenues are redistributed to fortunate citizens at a deadweight cost $\lambda$ per unit transferred.

As long as $\lambda$ is not too high, fortunate citizens in the majority maximize their payoff by imposing maximal equal taxes on every citizen and then redistributing surplus tax revenues to themselves. This is the case whenever ${ }^{13}$

13. A fortunate citizen is better off if a marginal increase in (equal) taxes results in a higher income after tax and redistribution. The deadweight loss in her own income of an increase in tax is

$$
\Delta \tau w\left(1-(1-\lambda)^{2}\right)
$$




$$
\frac{1-m_{l}}{\hat{m}} \geq \frac{\lambda(2-\lambda)}{(1-\lambda)^{2}} .
$$

We proceed first with this assumption.

Expected ex-ante utility of a representative citizen under the equal tax rule (net of distortionary costs from taxes and transfers) is then given by:

$$
\begin{aligned}
\Pi\left(m_{l}\right)= & w+\hat{m} B-(1-\hat{m}) b-\lambda w-\lambda\left[c+(b+w)\left(m_{l}-\hat{m}\right)\right] \\
& -\lambda\left(w(1-\lambda)-\left[c+(b+w)\left(m_{l}-\hat{m}\right)\right](1+\lambda)\right) \\
= & \mathscr{K}+\lambda^{2}(b+w)\left(m_{l}-\hat{m}\right),
\end{aligned}
$$

where $\mathscr{Y}$ is a constant.

The optimal majority rule $m_{l}^{e t}$ is, as always, the one that maximizes $\Pi\left(m_{l}\right)$ or equivalently $m_{l}$ subject to the budget constraint $\left(B C_{e t}\right)$. Therefore, whenever an interior solution obtains it is given by:

$$
m_{l}^{e t}=\frac{\hat{m}(w+b)+\frac{w(1-\lambda)}{1+\lambda}-c}{w+b} .
$$

Contrast this solution with the one obtained in the absence of an equal taxation restriction. In that case the budget condition is

$$
\left(B C_{\text {noet }}\right): w \hat{m}+\left(1-m_{l}\right) w(1-\lambda) \geq\left[c+b\left(m_{l}-\hat{m}\right)\right](1+\lambda) .
$$

The key difference between the two budget conditions is that under 'tax discrimination' the members of the majority (including harmed citizens) get a lower optimal tax rate to avoid redundant public transfers (taxing their income and then giving it back to them in the form of a public transfer). In fact, these citizens do not get taxed at all, while everyone else in equilibrium gets taxed the maximum rate. This latter observation follows from the fact that the ex-ante optimal majority rule is the largest $m_{l}$ for which $\left(B C_{\text {noet }}\right)$ holds:

The gain in higher subsidies is

$$
(1-\lambda)^{2} \Delta \tau w \frac{1-m_{l}}{\hat{m}},
$$

the net total tax revenues extracted from the minority shared equally among all fortunate citizens in the majority.

Therefore, higher (equal) taxes are preferred if and only if

$$
1-(1-\lambda)^{2} \leq(1-\lambda)^{2} \frac{1-m_{l}}{\hat{m}}
$$

or,

$$
\frac{1-m_{l}}{\hat{m}} \geq \frac{\lambda(2-\lambda)}{(1-\lambda)^{2}}
$$




$$
m_{l}^{\text {noet }}=\frac{\hat{m}\left(\frac{w}{1+\lambda}+b\right)+\frac{w(1-\lambda)}{1+\lambda}-c}{\frac{w}{1+\lambda}+b} .
$$

Inspection of $m_{l}^{\text {noet }}$ and $m_{l}^{e t}$ yields the result: $m_{l}^{e t}<m_{l}^{\text {noet }}$. In other words, an equal tax amendment results in a lower majority rule. The reason is that the equal tax restriction increases compensation costs by forcing agenda setters to make redundant distortionary public transfers. This distortion results in a lower majority rule, since at the margin a lower majority requires lower redundant public transfers. As one might expect from this discussion ex-ante welfare is lower under an equal tax amendment. Indeed, such an amendment does not really provide any protection to the minority against expropriation and without this amendment discriminatory taxation can entirely eliminate the deadweight costs of redundant taxation.

Would there be any benefits from an equal tax amendment if the opposite assumption

$$
\frac{1-m_{l}}{\hat{m}} \leq \frac{\lambda(2-\lambda)}{(1-\lambda)^{2}}
$$

holds? In that case the agenda setters want to set as low as possible a tax rate subject to satisfying the budget condition. Hence, the amendment does indeed provide some form of protection against expropriation of the minority for some majority rules $m_{l}$.

Since agenda setters want to minimize the overall tax burden under this scenario the optimal majority rule is the one that minimizes redundant transfers and is given by $m_{l}^{e t}=\hat{m}$. Indeed, under this rule the equilibrium tax rate is given by

$$
\tau^{*}=\frac{c}{w(1-\lambda)^{2}},
$$

and expropriation of the minority is reduced to a minimum. We summarize our analysis in the proposition here:

Proposition 4 An equal tax rule provides no minority protections against expropriation, results in a lower majority rule

$$
m_{l}^{e t}=\frac{\hat{m}(w+b)+\frac{w(1-\lambda)}{1+\lambda}-c}{w+b},
$$

and lower ex-ante welfare when deadweight costs of transfers are relatively low and satisfy the condition: 


$$
\frac{1-m_{l}}{\hat{m}} \geq \frac{\lambda(2-\lambda)}{(1-\lambda)^{2}} .
$$

Otherwise, an equal tax rule induces agenda setters to minimize the tax burden ex-post, results in a lower majority rule $m_{l}^{e t}=\hat{m}$, and higher ex-ante welfare.

4.1.3 Tax Limits Another way of providing minority protections is through tax ceilings or minimum income exemptions. Are these equally undesirable? In other words, is the optimal tax ceiling $\tau^{*}=1$ ? To see the effects of such protections in our model suppose that the constitution can impose both a majority rule $m_{l}$ and an upper bound $\tau$ on the fraction of individual wealth that can be taxed. For a given $\tau$ the budget condition now becomes:

$$
\left(B C_{t l}\right): \hat{m} w+\left(1-m_{l}\right) \tau w(1-\lambda) \geq c+b\left(m_{l}-\hat{m}\right) .
$$

And the expected ex-ante utility of a representative individual under the veil of ignorance, is now:

$$
\Pi\left(m_{l}, \tau\right)=w+\hat{m} B-(1-\hat{m}) b-\lambda\left(1-m_{l}\right) \tau w .
$$

The optimal constitution $\left(m_{l}, \tau\right)$ is the one that maximizes $\Pi\left(m_{l}, \tau\right)$ subject to $\left(B C_{t l}\right)$. Using the fact that the budget constraint is binding at the optimum, we can substitute for $\left(1-m_{l}\right) \tau$ as a function of $m_{l}$ alone into the maximand. Then the optimal rule $m_{l}^{t l}$ is the solution to:

$$
\min _{m_{l} \geq \hat{m}}\left(1-m_{l}\right) \tau=\frac{c+b\left(m_{l}-\hat{m}\right)}{w(1-\lambda)}-\frac{\hat{m}}{(1-\lambda)} .
$$

We thus immediately obtain:

$$
m_{l}^{t l}=\hat{m} .
$$

Substituting for $m_{l}^{t l}$ in the budget condition we also obtain the optimal tax ceiling

$$
\tau^{t l}=\frac{c-\hat{m} w}{w(1-\hat{m})(1-\lambda)} .
$$

Note that $\tau^{*}<1$ under assumption A1.

Thus, once again we obtain an optimal majority rule which is strictly less than the optimal rule under no tax limits. But, now the lower majority rule results in a welfare improvement. Indeed the previous solution $\tau=1$ and $m_{l}=$ $m_{l}^{*}$ is still attainable here but is shown to be dominated.

So, why do tax ceilings improve ex-ante welfare? The reason is that tax ceilings are a more direct way of limiting expropriation of the minority than a majority rule. By controlling expropriation directly through $\tau$ it is possible to avoid including harmed citizens in the majority, which would require costly transfers, and limit expropriation of the minority to a level just sufficient to raise sufficient revenues to cover the cost of the public good. 
REMARK There is also a dark side to tax limits when $m_{i}$ is random. In that case, some states of nature may occur in which it is not possible to raise enough funds to cover the cost of the public good. If a state of nature arises with $m_{i}$ such that

$$
\begin{gathered}
\frac{c-m_{i} w}{w\left(1-m_{i}\right)(1-\lambda)}=1, \\
B m_{i}-\left(1-m_{i}\right) b \gg c,
\end{gathered}
$$

and this state of nature occurs with a high probability, then it may be ex-ante optimal to set $\tau=1$. In general, however, such a knife-edge case is unlikely and some tax limits will generally be optimal.

\subsection{Vote Trading}

Our model can be used to discuss the issue of whether or not vote trading should be allowed. Vote trading used to be a common practice in the United States and the United Kingdom until the end of the nineteenth century when secret ballots were introduced. It is commonly seen as undemocratic by political scientists, but many free-market economists advocate the introduction of vote trading as a way of introducing market efficiency into the political sphere. Economists favoring vote trading argue that it increases aggregate welfare by allowing for the expression of intensity of preferences. Someone without strong preferences over the political outcome can sell her vote to someone with bigger stakes (see e.g., Casella 2002). Opponents of vote trading, on the other hand, argue that it exacerbates the inequality between rich and poor and that it undermines pluralism.

Without attempting to resolve this debate, our analysis highlights another important drawback of vote trading, which has been elegantly expressed in general terms as follows by Thomas Schelling:

What is a secret ballot but a device to rob the voter of his power to sell his vote? It is not alone the secrecy, but the mandatory secrecy, that robs him of his power. He not only may vote in secret, but he must if the system is to work. He must be denied any means of proving which way he voted. And what he is robbed of is not just an asset that he might sell; he is stripped of his power to be intimidated; he is made impotent to meet the demands of blackmail. There may be no limit to violence that he can be threatened with if he is truly free to bargain away his vote, since the threatened violence is not carried out anyway if it is frightening enough to persuade him. But when the voter is powerless to prove that he complied with the threat, both he and those who would threaten him know that any punishment would be unrelated to the way he actually voted. And the threat being useless, goes idle. [Schelling 1960, p. 148$]^{14}$

14. We thank an anonymous referee for bringing this passage to our attention. 
In less dramatic words, in our model vote trading tends to increase the scope for expropriation of voters. Indeed if one allows for vote trading, the agenda setters will be able to extract the whole transferable surplus from all other voters by threatening to push a majority member into the minority (in other words, by playing on Bertrand competition for the tradeable right to belong to the majority). Thus, in our model vote trading is inefficient as it increases the deadweight loss from expropriation under majority voting.

More formally, let the agenda setters be the fortunate as in the basic model, and suppose that $m_{i} \equiv \hat{m}$ and suppose that the majority rule is such that $m_{l}>$ $\hat{m}$. If there is no vote trading then the agenda setters must offer a compensating transfer $b$ to all 'harmed citizens' doing the majority coalition. But with vote trading the agenda setter can buy $N\left(m_{l}-\hat{m}\right)$ 'harmed citizen' votes instead of bribing a fraction $\left(m_{l}-\hat{m}\right)$ of 'harmed citizens' into voting for his proposal. The total demand for 'harmed citizen' votes is then $N\left(m_{l}-\hat{m}\right)$, but the total supply is $N(1-\hat{m})$. In other words, as long as $m_{l}<1$ the total supply exceeds demand. With excess supply of votes the equilibrium price will be equal to zero and the agenda setters can expropriate all 'harmed citizens' without compensating any of them as long as everyone believes that the agenda setters will be able to bring together the required majority of votes. This is true for all majority rules barring unanimity. Therefore, under vote trading it is easier to expropriate the minority. Moreover an increase in the majority requirement is no protection unless the rule is unanimity. Thus, under vote trading the expected ex-ante payoff

$$
\Pi^{1, z t}\left(m_{l}\right)=w+\hat{m} B-(1-\hat{m}) b-\lambda\left(1-\min \left(\hat{m}, m_{l}\right)\right) w-c,
$$

is lower than the ex-ante payoff $\Pi^{1}\left(m_{l}\right)$ in the absence of vote trading.

Although this observation follows straightforwardly from our analysis it is sufficiently important to be worth highlighting in the following proposition.

Proposition 5 Vote trading increases the scope for expropriation and lowers ex-ante expected payoffs for the representative individual. Only unanimity constitutes a protection against expropriation.

A parallel can be drawn here with the literature on corporate takeovers (see Grossman and Hart 1980, 1988). For any majority rule (except unanimity) a value decreasing takeover can always succeed. The reason is the same as here: excess supply of shares tendered at a price per share marginally higher than the post-takeover value. Interestingly, some corporate law scholars have advocated banning tender offers and allowing only corporate control changes through majority voting in proxy contests because of these undesirable outcomes of tender offers (see Lipton and Rowe 2001).

\subsection{Federalism versus Separatism}

Our analysis also sheds light on the issue whether several independent states (or regions) should federate into a single legislative entity. It has often been suggested that if southern states of the United States had been able to secede, 
then the Black minority would have been oppressed for much longer and the civil rights movement might not have succeeded in those states. It is the majority in Northern states supporting the abolition of slavery and later the civil rights movement that have constituted the best protection for minorities in the South and elsewhere in the United States. This example vividly illustrates the potential benefit of belonging to a federation: a minority in one state can find protections in similarly minded majorities in other states. We provide a simple formal analysis of this idea in this subsection.

Our analysis points to the following effects. On the one hand, federalism reduces the risk of being in the exploited minority. This in turn leads to a less stringent majority rule and therefore facilitates public good provision. On the other hand, a lower majority rule under federalism can also result in an increase in equilibrium expropriation.

To see the costs and benefits of federalism more precisely consider the simple scenario of two identical states that share the same ex-ante uncertainty over the costs and benefits of public good provision. Assume that in each region the fraction of fortunate citizens $m_{i}$ is random and that it is independently distributed across the two regions as follows:

$$
m_{i}= \begin{cases}\bar{m} & \text { with probability } q \\ \underline{m} & \text { with probability }(1-q),\end{cases}
$$

where $q<1 / 2$ and $\underline{m}<\bar{m}$.

We begin by deriving the equilibrium outcome under separatism. We then compare this outcome to the one under federalism. Finally, we briefly discuss the role of bicameralism or a second legislature representing the interests of member states in a federation by modeling the bicameral constitution in the reduced form of a veto right of each state.

4.3.1 Separatism Consider first each state separately. From our analysis in Section 3.1, we know that the optimal majority rule $m_{l}$ in each state solves the following maximization program:

$$
\begin{aligned}
\max _{m l} \Pi\left(m_{l}\right)=w-w \lambda\left(1-m_{l}\right)+q[ & \bar{m} B-(1-\bar{m}) b-c] \cdot \Lambda\left(\bar{m}, m_{l}\right) \\
& +(1-q)[\underline{m} B-(1-\underline{m}) b-c] \cdot \Lambda\left(\underline{m}, m_{l}\right),
\end{aligned}
$$

(where $\Lambda=\Lambda\left(m_{i}, m_{l}\right)$ is the indicator function taking the value $\Lambda=1$ whenever the budget constraint $(B C)$ is satisfied, and $\Lambda=0$ otherwise).

Assuming that conditions (4) and (5) hold both for $m_{i}=\underline{m}$ and $m_{i}=\bar{m}$ then the optimal majority rule $m_{l}$ can only take the following two values:

$$
\underline{m}_{l}=\mu_{l}(\underline{m})=\frac{(w+b) \underline{m}+w(1-\lambda)-c}{w(1-\lambda)+b},
$$

or 


$$
\bar{m}_{l}=\mu_{l}(\bar{m})=\frac{(w+b) \bar{m}+w(1-\lambda)-c}{w(1-\lambda)+b} .
$$

Under the lower majority rule the public good is always produced and ex-ante expected payoffs are:

$$
\begin{aligned}
\Pi\left(\underline{m}_{l}\right)=w-\frac{\lambda w[b(1-\underline{m})+w \underline{m}-c]}{w(1-\lambda)+b}+ & q[\bar{m} B-(1-\bar{m}) b-c] \\
& +(1-q)[\underline{m} B-(1-\underline{m}) b-c] .
\end{aligned}
$$

Under the higher majority rule the public good is only produced when $m_{i}=$ $\bar{m}$ and ex-ante expected payoffs are

$$
\Pi\left(\bar{m}_{l}\right)=w-\frac{\lambda w[b(1-\bar{m})+w \bar{m}-c]}{w(1-\lambda)+b}+q[\bar{m} B-(1-\bar{m}) b-c] .
$$

Comparing the payoffs in equations (6) and (7) we observe that the stricter majority rule is optimal if and only if

$$
\frac{\lambda w(w-b)}{w(1-\lambda)+b}(\bar{m}-\underline{m}) \geq(1-q)[\underline{m} B-(1-\underline{m}) b-c] .
$$

This is a very intuitive condition. If the deadweight costs of expropriating the minority - as measured by $w$ and/or $\lambda$-are large and a high realization for $m_{i}$ is likely, then it is optimal to set a stringent majority requirement to reduce expropriation costs. Note in particular that when $m_{i}=\bar{m}$ is likely then there is only a small risk of not producing the public good in the event where $m_{i}=\underline{m}$. In the remaining part of this subsection we shall restrict attention to parameter values such that condition (8) holds. Then, under separatism, the net ex-ante payoff of a representative individual is equal to:

$$
\Pi^{s e p}=q[\bar{m} B-(1-\bar{m}) b-c]+w-w \lambda\left(1-\mu_{l}(\bar{m})\right) .
$$

4.3.2 Comparing Federalism and Separatism What happens if the two regions decide to federate? First, the aggregate fraction of fortunate citizens $M_{s}$ in the federation will be distributed according to:

$$
M_{s}=\left\{\begin{array}{l}
\overline{\bar{m}} \quad \text { with probability } q^{2} \\
\frac{\bar{m}+\underline{m}}{2} \quad \text { with probability } 2 q(1-q) \\
\underline{m} \quad \text { with probability }(1-q)^{2} .
\end{array}\right.
$$

With this distribution of $M_{s}$ it remains suboptimal to set the majority rule equal to $\underline{m}_{l}$ as this would expose the representative individual to excessive expropriation. However, for suitable parameter values it will be optimal to set the majority rule in the federation equal to: 


$$
\mu_{l}\left(\frac{\bar{m}+\underline{m}}{2}\right)=\frac{(w+b)\left(\frac{\bar{m}+\underline{m}}{2}\right)+w(1-\lambda)-c}{b+w(1-\lambda)},
$$

in order to facilitate public good provision. In that case, the ex-ante mean payoff of an individual under federalism will be equal to:

$$
\begin{aligned}
\Pi^{f e d}= & q^{2}[\bar{m} B-(1-\bar{m}) b-c]+2 q(1-q) \\
& \times\left[\frac{\bar{m}+\underline{m}}{2} B-\left(1-\frac{\bar{m}+\underline{m}}{2}\right) b-c\right]+w-w \lambda\left(1-\mu_{l}\left(\frac{\bar{m}+\underline{m}}{2}\right)\right)
\end{aligned}
$$

Comparing the payoffs under separatism in (9) and federalism in (10) we get:

$$
\Pi^{\text {fed }}-\Pi^{\text {sep }}=q(1-q)[\underline{m} B-(1-\underline{m}) b-c]-w \lambda \Omega,
$$

where:

$$
\Omega=\bar{m}_{l}-\mu_{l}\left(\frac{\bar{m}+\underline{m}}{2}\right)>0 .
$$

Thus, by relaxing the majority requirement, federalism increases the probability of public good provision, but does it at the cost of increasing the total deadweight loss from expropriation. In particular when $q$ is sufficiently large-so that the expected gain of increasing public good provision under federalism $(1-q)(\underline{m} B-(1-\underline{m}) b-c)$ is smaller than the expected expropriation cost $w \lambda \Omega$-separatism will prevail. On the other hand, if $q$ is small and/or the net expected benefit from public good provision $\underline{m} B-(1-\underline{m}) b-c$ is large, the opposite is true and federalism will tend to dominate. ${ }^{15}$ This establishes:

PROPOSITION 6 Under Federalism the overall risk of expropriation is reduced and the optimal majority requirement is (weakly) lower than under Separatism. This gives rise to (weakly) higher public good provision. Federalism dominates Separatism when the expected gain from increasing public good provision is greater than the increase in aggregate cost from expropriation under a lower majority requirement. That is, when $\underline{m} B-(1-\underline{m}) b-c$ is sufficiently large and q sufficiently small.

In other words, what federalism does is to increase the blocking power of harmed individuals by merging them with fortunate citizens from another region or state. This reduces the need for a high majority rule. Under a lower majority rule fewer harmed citizens will need to be compensated ex-post. This in turn makes it possible to have the public good produced more often than under

15. Note that majority rules $\mu_{l}(\underline{m})$ and $\mu_{l}(\bar{m})$ under federalism cannot give rise to higher expected payoffs than under separatism since these rules would only replicate an outcome attainable under separatism. 
separatism. But, of course, it also means that equilibrium expropriation costs will be higher.

4.3.3 The Scope for Bicameralism The issue of whether one should have one or two chambers, and of what role should be assigned to the second chamber, have long been the subject of intense debates among Constitutional Law scholars. One view is that a second chamber may help monitor the first chamber and provide a further opportunity to amend or reject unsatisfactory reform projects. For example, this is broadly what the French "Senat" is supposed to accomplish, although it is often argued that what this second chamber actually does is to increase the power of vested interests, especially that of landowners. An alternative view is that a second chamber may help control or reduce inequality across different regions or states within a country. This view is probably best exemplified by the German Bundesrat, whose main purpose is to preserve a balance between the various German "Länder." Interestingly, the model of federalism outlined above, allows us to discuss some pros and cons of a German-type of bicameral system.

Thus consider the above model with two states that share the same ex-ante uncertainty over the costs and benefits of public good provision, with the fraction of fortunate citizens $m_{i}$ in each state being random with:

$$
m_{i}= \begin{cases}\bar{m} & \text { with probability } q \\ \underline{m} & \text { with probability }(1-q),\end{cases}
$$

where $q<1 / 2$ and $\underline{m}<\bar{m}$. And suppose that it is optimal ex ante for the two states to federate into one country. Then, introducing a second chamber in which there is a one state-one vote rule and a qualified majority of states for a reform to pass, in our model with only two states amounts to introducing a veto power for each separate state.

Suppose that the federal constitution specifies that once the required majority of individuals in the federation has voted in favor of the public good provision, the decision can be vetoed by a representative from each state. In this case when $m_{i}=\bar{m}$ in one state (say state 1 ) and $m_{i}=\underline{m}$ in the other state (say state 2), then the representative in state 2 will require an additional compensation $E$ (say, $E=(1-\underline{m}) b-\underline{m} B$ ) in order not to veto the decision. However, imposing such ex-post redistribution will tighten the budget condition for public good provision, which in turn will lead to a lower majority rule in equilibrium. Therefore, a higher expected deadweight loss from taxation of the minority and lower ex ante welfare may result from such a veto right. This result should not be surprising, as bicameralism in this case is similar to allocating amendment rights to representatives from each state.

We have just pointed to a negative welfare effect of bicameralism. But we can also point to at least two positive effects in the context of our model. First, as with amendment rights, the redistributive impact of bicameralism may 
enhance welfare if individuals are risk averse. Second, bicameralism may not only impose additional redistribution across regions ex post. It may also prevent unequal (average) taxation of the two regions. Thus, bicameralism may prevent the majority from raising more than the amount $(1-\bar{m}) w$ of taxes in both states. As with tax limits, this should limit the scope for costly expropriation and thereby increase ex-ante welfare.

\section{Conclusions}

In this paper, we have developed an incomplete contracting framework to characterize an optimal decision rule under the veil of ignorance. We have established that: (1) the optimal majority rule results from a trade-off between minimizing the costs of compensating vested interests on the one hand and minimizing the scope for expropriation on the other hand; (2) the optimal majority rule depends on the characteristics of the reform (size and distribution of gains and losses across individuals) and on underlying characteristics of the economy (taxation cost, individual wealth, exposure to expropriation); (3) the trade-off between compensation costs and expropriation governs other aspects of constitutional design such as amendment rights, tax limits or equal tax rules, vote trading, federalism, and bicameralism.

Our analysis in this paper can be extended in several interesting directions. First, other aspects of constitution design, such as the choice of electoral rules (proportional versus majoritarian), term limits for politicians in office, the balance of powers between the legislative, executive, and judiciary powers, and the role of balanced budget provisions can be analyzed using our framework. Whereas specific models may be required to analyze each of these issues, they ought to rely on the same incomplete contracting methodology and to encompass similar trade-offs as in this paper.

Second, our framework can be adapted to analyze the optimal choice of decision rule to govern constitutional change. A natural way of looking at constitutional change within our incomplete contract setting is as a mechanism to renegotiate the social contract.

Third, our incomplete social contract methodology may also be relevant for the analysis of collective decision making and the design of governance structures in other types of institutions and organizations such as private committees, cooperatives, firms and bankruptcy procedures. In particular, our approach might shed light on observed differences across the corporate charters of public versus privately held companies, for example with regard to minority shareholder protection. To the extent that shareholders in public companies can more easily exit through selling their shares, the scope for expropriating minority shareholders should be relatively smaller in such companies. Our analysis would therefore predict that one should observe more stringent protection rules in privately held firms. Analyzing this and other aspects of the design of corporate charters appears to be another promising avenue for further research. 


\section{References}

Aghion, Phillipe, Alesina, A., and Trebbi, F. (2002). "Endogenous Political Institutions," mimeo. Cambridge, Massachusetts: Harvard University.

Aghion, P. and Bolton, P. (2002). "Incomplete Social Contracts," mimeo. Princeton, New Jersey: Princeton University.

Baldwin, R., Berglof, E., Giavazzi, F., and Widgren, M. (2001). Nice Try: Should the Treaty of Nice Be Ratified? London: CEPR.

Baron, D. and Ferejohn, J. (1987). "Bargaining and Agenda Formation in Legislatures." American Economic Review, pp. 303-309.

Baron, D. and Ferejohn, J. (1989). "Bargaining in Legislatures." American Political Science Review, 83 (4), pp. 1181-1206.

Buchanan, J. M. and Tullock, G. (1965). The Calculus of Consent: Logical Foundations of Constitutional Democracy. Ann Arbor, MI: University of Michigan Press.

Caplin, A. and Nalebuff, B. (1988). “On 64\%-Majority Rule.” Econometrica, 56, pp. 787-814.

Casella, A. (2002). Storable Votes, mimeo. New York: Columbia University.

Dasgupta, P. and Maskin, E. (1997). "Preference Domains and Majority Voting," mimeo. Cambridge, Massachusetts: Harvard University.

Erlenmaier, U. and Gersbach, H. (1999). "Flexible Majority Rules.” mimeo. Heidelberg, Germany: University of Heidelberg. 〈http://www.rzuser.uni-heidelberg.de/ hgersbac/ wipo/working_papersa.html $>$.

Gersbach, H. (2002). "Democratic Mechanisms: Double Majority Rules and Flexible Agenda Costs." mimeo. Heidelberg, Germany: University of Heidelberg. http://www.rzuser.uniheidelberg.de/ horgersbac/wipo/working_papersa.html.

Grossman, H. and Hart, O. (1980). "Takeover Bids, the Free Rider Problem and the Theory of the Corporation," Bell Journal of Economics 11: 42-64.

Grossman, H. and Hart, O. (1988). "One Share One Vote and the Market for Corporate Control," Journal of Financial Economics 20: 175-202.

Harsanyi, J. (1955). "Cardinal Welfare, Individual Ethics and Interpersonal Comparability of Utility." Journal of Political Economy, 61, pp. 309-321.

Laffont, J.-J. (1995). "Industrial Policy and Politics." International Journal of Industry Organization, 14, pp. 1-27.

Lipton, M. and Rowe, P. (2001). "Pills, Polls and Professors: A reply to Professor Gilson." Working paper No: CLB-01-006, New York University Center for Law and Business.

Mirrlees, J. (1971). "An Exploration in the Theory of Optimum Income Taxation." Review of Economic Studies, 38, pp. 175-208.

Persson, T., Roland, G., and Tabellini, G. (1997). "Separation of Powers and Political Accountability," Quarterly Journal of Economics, 112, pp. 1163-1202.

Persson, T. and Tabellini, G. (2000). Political Economics. Cambridge, Massachusetts: MIT Press.

Rae, D. (1969). "Decision Rules and Individual Values in Constitutional Choice." American Science Review, 63, pp. 40-56.

Romer, T. and Rosenthal, H. (1983). "A Constitution for Solving Asymmetric Externality Games." American Journal of Political Science, 27, pp. 1-26.

Rousseau, J.-J. (1762). The Social Contract. Translated by C.E. Vaughan. Reprint, Manchester, UK, 1947.

Schelling, T. (1960). The Strategy of Conflict. Cambridge, Massachusetts: Harvard University Press.

Taylor, M. J. (1969). "Proof of a Theorem on Majority Rule." Behavioral Science, 14, pp. $228-231$. 